\title{
Design and development of sustained-release glyburide-loaded silica nanoparticles
}

\author{
JAYESH S PATIL, PRITAM B PATIL, PRAVIN SONAWANE and JITENDRA B NAIK (D) * \\ Department of Pharmaceutical Technology, University Institute of Chemical Technology, \\ North Maharashtra University, Jalgaon 245001, India
}

MS received 1 April 2016; accepted 2 July 2016

\begin{abstract}
The aim of this study was to develop sustained-release glyburide-loaded silica nanoparticles. Silica nanoparticles were synthesized by the sol-gel method using tetra-ethyl ortho-silane as a precursor. Glyburide was successfully entrapped in synthesized silica nanoparticles. To identify the effect of independent variables (concentration of silica and concentration of glyburide) on encapsulation efficiency and drug release (dependent variables), $3^{2}$ (three level-two factors) response surface methodology was employed. Silica nanoparticles and glyburide-loaded silica nanoparticles were characterized by scanning electron microscopy, BET surface area, X-ray diffraction and Fourier transformed infrared spectroscopy. The optimum values of encapsulation efficiency and drug release were 70.21 and $87.8 \%$ over $24 \mathrm{~h}$, respectively; these values agree well with predicted values obtained by response surface methodology. Glyburide-loaded silica nanoparticles were successfully prepared without any incompatibility and seem to be promising for sustained-release drug delivery application and better patient compliance.
\end{abstract}

Keywords. Silica nanoparticles; glyburide; sustained release; sol-gel method.

\section{Introduction}

Since the last few decades, nanoparticles are the most promising applicant in the drug delivery systems. Metal oxide nanoparticles have proved their importance in the drug delivery of cancer imaging, i.e., diagnosis. They act as a carrier for drug and have good biocompatibility or biodegradability. Silica nanoparticles (SiNPs) act as a promising drug carrier primarily due to their unique tunable structural properties such as good size control [1] and biocompatibility, and can be safely taken up by living cells through endocytosis. SiNPs are stable due to the $\mathrm{Si}-\mathrm{O}$ bond in their structure [2]. They have a large surface-to-volume ratio; therefore they can transport large quantities of drugs to specific sites [3]. SiNPs are simple to synthesize by different methods such as chemical vapour deposition, Pickering emulsion, sol-gel method and Stober method [4]. These synthesized SiNPs are highly demanded nanomaterial in drug delivery application due to their uniform particle size and surface functionalization property [5,6]. A coupling agent is used for the functionalization of SiNPs; wherever silane group is present, mercaptopropyl, amino-propyl and methyl/ethyl groups are commonly used to prepare surface-functionalized SiNPs [3]. In the present study, we have used the 3-aminopropyl triethoxysilane (APTES) as a surface-functionalized material.

Glyburide (GBL) is the most commonly used antihyperglycemic agent of class sulphonylurea having half-life

\footnotetext{
*Author for correspondence (jbnaik@nmu.ac.in)
}

$1.5-1.8 \mathrm{~h}$ taken orally to treat type II diabetes. GBL helps in release of insulin by stimulating $\beta$ cells of pancreas $[7,8]$ and inhibits ATP-sensitive $\mathrm{K}^{+}\left(\mathrm{K}_{\mathrm{ATP}}\right)$ channels in $\beta$ cells of pancreas [9]. Long-term treatment of GBL should be avoided in patients with chronic kidney disease [10] and active ischemic heart disease [11]. GBL shows an oral bioavailability and is extensively metabolized in the liver [12], indicating that the first pass effect of GBL is expected to be slight, and high plasma protein binding (99.8\%) [13].

The aim of this work was to develop sustained-release glyburide-loaded silica nanoparticles (Si-GBL). Three-level factorial design was engaged to investigate the effect of two factors, viz., amount of SiNPs and GBL, on percentage encapsulation efficiency (EE) and drug release (DR). An in vitro release study was carried out to evaluate the influence of all physicochemical and DR parameters of Si-GBL.

\section{Materials and methods}

\subsection{Materials}

GBL was kindly gifted by USV limited (Mumbai, India). Cetyl trimethyl ammonium bromide (CTAB), tetra-ethyl ortho-silane (TEOS) and 3-amino propyl trimethoxysilane were procured from Sigma Aldrich (Mumbai, India). Ammonia, di-ethyl ether and methanol were purchased from Rankem Pvt. Ltd. (Mumbai, India) and all other chemicals were of analytical grade and used as provided. 


\subsection{Methods}

2.2a Synthesis of silica nanoparticles: SiNPs were synthesized by the sol-gel method using TEOS as a precursor [14]. Briefly, $1.2 \mathrm{~g}$ of CTAB with $16 \mathrm{ml}$ of deionized water was taken in a two-neck flask. Then $80 \mathrm{ml}$ of di-ethyl ether was added to the water. It was kept on a magnetic stirrer for 15-20 min by wrapping one end of the flask with aluminium foil and the other with a stop cock. After that $2 \mathrm{ml}$ of ammonia was added to the mixture under vigorous stirring till a homogeneous mixture formed. When the solution became homogeneous, $4 \mathrm{ml}$ of TEOS was added through the stop cock, keeping other end closed, stirring was continued for $24 \mathrm{~h}$. The synthesized material was centrifuged at $19,000 \mathrm{rpm}$ for $5 \mathrm{~min}$ and washed with deionized water. The centrifugation and washing process was carried out $4-5$ times till a clear solution was obtained. The final product was collected in a Petri dish and kept in an oven overnight at $60 \pm 1{ }^{\circ} \mathrm{C}$ for the removal of water. The final product was calcinated at $550^{\circ} \mathrm{C}$ for $6 \mathrm{~h}$ and used for further characterization $[15,16]$.

2.2b Synthesis of glyburide-loaded silica nanoparticles: SiNPs $(500 \mathrm{mg}$ ) were added in $40 \mathrm{ml}$ of ethanol. The specified quantity of drug was added according to batches given by the DESIGN-EXPERT software in it and stirred up to $24 \mathrm{~h}$. Amino-propyl tri-methoxysilane (APTMS) was added and the whole mixture was stirred further for $8 \mathrm{~h}$. Then the mixture was centrifuged at $10,000 \mathrm{rpm}$ for $20 \mathrm{~min}$ and air dried. The final dried formulation was used for further analysis such as drug loading and DR.

\section{Experimental}

To evaluate the effect of several independent variables on responses, $3^{2}$ (three level-two factor) response surface methodology is a significant tool. Based on screening of various factors, the independent variables selected were the amount of silica $\left(X_{1} \mathrm{mg}\right)$ and GBL $\left(X_{2} \mathrm{mg}\right)$, which were varied at three levels $(-1,0,+1) . Y 1($ EE\%) and $Y 2($ DR\%) are the dependent factors. DESIGN-EXPERT software (StatEase Inc., Minneapolis) was used to perform the experimental study. The design matrix with dependent and independent variables is shown in table 1 . The effect of independent variables on responses was modelled by the following equation:

$$
Y=\beta_{0}+\beta_{1} X_{1}+\beta_{2} X_{2}+\beta_{3} X_{1} X_{2}+\beta_{4} X_{1}^{2}+\beta_{5} X_{2}^{2},
$$

where $Y$ is the response, $\beta_{0}$ is the intercept and $\beta_{1}-\beta_{5}$ are regression coefficients. $X_{1}, X_{2}$ are individual effects. $X_{1} X_{2}$ is the interaction effect and $X_{1}^{2}, X_{2}^{2}$ are the quadratic effects. The significance of the model was evaluated at $P<0.05$ level [17-20].

\section{Characterizations}

\subsection{X-ray diffraction (XRD) analysis}

The nature (crystalline/amorphous) of pure GBL, SiNPs and Si-GBL was examined using an X-ray diffractometer (Bruker, D8 Advanced, Germany) with $\mathrm{Cu} \mathrm{K} \alpha$ radiation ( $\lambda=$ $1.5406 \AA$ ). The anode $\mathrm{X}$-ray tube was operated at $40 \mathrm{kV}$ and $40 \mathrm{~mA}$. The samples were analysed over the $2 \theta$ angle range of $4-80^{\circ}$ at a step size of $0.03 \mathrm{~s}^{-1}$ [21].

\subsection{Field emission scanning electron microscopy (FE-SEM) analysis}

The shape, size and surface morphology of Si-GBL were examined by FE-SEM (FESEM-S 4800, Hitachi, Japan) at a working distance of $8.6-8.8 \mathrm{~mm}$ and accelerating voltage of $15.0 \mathrm{kV}$ [22]. For the morphological study, the nanoparticles were coated with gold and mounted on a brass stub using a

Table 1. Encapsulation efficiency (EE, \%) and drug release (DR, \%) over $24 \mathrm{~h}$.

\begin{tabular}{lcccc}
\hline Experimental run & Silica $(\mathrm{mg})$ & Glyburide $(\mathrm{mg})$ & EE $(\%)$ & DR (\%) \\
\hline F1 & 1 & 1 & 70.21 & 87.8 \\
F2 & 0 & 0 & 74 & 82 \\
F3 & 1 & 0 & 66 & 70 \\
F4 & 0 & 0 & 73 & 84 \\
F5 & 0 & 0 & 73 & 82 \\
F6 & 0 & 0 & 74.4 & 82.9 \\
F7 & 1 & -1 & 62 & 68.8 \\
F8 & -1 & -1 & 76 & 87 \\
F9 & 0 & 0 & 73.8 & 82.6 \\
F10 & -1 & 1 & 80 & 82 \\
F11 & 0 & -1 & 78 & 83 \\
F12 & -1 & 1 & 78 & 84.5 \\
F13 & 0 & & & \\
Coded levels & & Medium level (0) & High level (+1) & \\
Independent variable & Low level (-1) & 300 & 500 & \\
\hline$X_{1}=$ Silica (mg) & 100 & 400 & 500 & \\
$X_{2}=$ Glyburide (mg) & 300 & &
\end{tabular}


double-sided adhesive tape under vacuum in an ion sputter (Hitachi E1010) to make them electrically conductive.

\subsection{Pore size and surface area analysis}

The pore size and surface area of synthesized SiNPs were analysed using a BET analyzer. The sample cell with the glass tube, frit and cap was dried and weighed before addition of sample in the tube (cell weight). After addition of the sample in the sample cell using a long stemmed funnel, the sample was loaded in BELPREP vac II and degassed at $165^{\circ} \mathrm{C}$ for $1 \mathrm{~h}$ at a vacuum pressure of $10-20 \mathrm{kPa}$. The sample cell was then removed and weighed. The difference in weight gave the sample quantity.

\subsection{Fourier transform infrared (FTIR) spectroscopy}

To examine the drug-polymer interaction the infrared spectra of pure GBL, SiNPs and Si-GBL were obtained using a Fourier transformed infrared spectroscopy (FTIR) spectrophotometer (FTIR-8400; Shimadzu, Asia Pacific Pvt. Ltd., Singapore) by using the potassium bromide $(\mathrm{KBr})$ pellet method. For this, the sample $(1 \mathrm{mg})$ was mixed with $\mathrm{KBr}$ $(40 \mathrm{mg})$ and compressed manually into a disc in a $\mathrm{KBr}$ press. Spectra were recorded in the wavelength region of $4000-400 \mathrm{~cm}^{-1}$.

\subsection{EE and DRL}

The amount of GBL in Si-GBL was determined using a UV spectrophotometer (Hitachi U2900). EE percent was calculated using the following equation:

$\mathrm{EE}(\%)=\frac{\text { Weight of drug determined }(\mathrm{mg})}{\text { Weight of drug added }(\mathrm{mg})} \times 100$.

DR study of GBL was carried out in 7.4 phosphate buffer solution at $37 \pm 5^{\circ} \mathrm{C}$. Si-GBL equivalent to $50 \mathrm{mg}$ of $\mathrm{GBL}$ were filled in a pretreated dialysis bag. These bags were placed in the dissolution vessel of an eight-station fully calibrated dissolution test apparatus (Electrolab auto-sampler dissolution tester TDT-08L)). Each vessel contained $900 \mathrm{ml}$ of phosphate buffer solution and stirred at a speed of $100 \mathrm{rpm}, 37 \pm 5^{\circ} \mathrm{C}$. Aliquots of dissolution medium $(5 \mathrm{ml})$ were withdrawn at a predetermined time interval and replenished with an equivalent volume of fresh dissolution medium to maintain the sink condition. GBL concentration was analysed using a UV spectrophotometer at $225 \mathrm{~nm}$.

\section{Result and discussion}

\subsection{X-ray diffraction}

XRD patterns of pure GBL, SiNPs and Si-GBL are shown in figure 1. Pure GBL (figure 1a) showed distinct peaks at scattering angle $(2 \theta)$ of $9.912,10.769,15.293,18.046,20.02$, $22.114,24.20,28.39,31.44,37.72,45.63$ and $48.44^{\circ}$, which confirmed the crystalline nature $(72 \%)$. The XRD pattern of SiNPs (figure 1b) as well as Si-GBL of optimized batch (experimental run 10-figure 1c) showed amorphous nature (60 and 52\%, respectively). The amorphization of optimized formulation reveals that the majority of the drug is entrapped within the SiNPs and dispersed at a molecular level. Thus, XRD analysis suggested that the degree of crystallinity of GBL was reduced and most of the drug existed in amorphous state in formulation.

\subsection{Field-emission scanning electron microscopy (FE-SEM)}

The surface characteristics of Si-GBL were examined by FE-SEM. Figure $2 \mathrm{a}$ shows that the Si-GBL are discrete and spherical in nature with particles in the size range of 250 $590 \mathrm{~nm}$. The porous surface is clearly observed on the SiNPs in figure $2 b$.

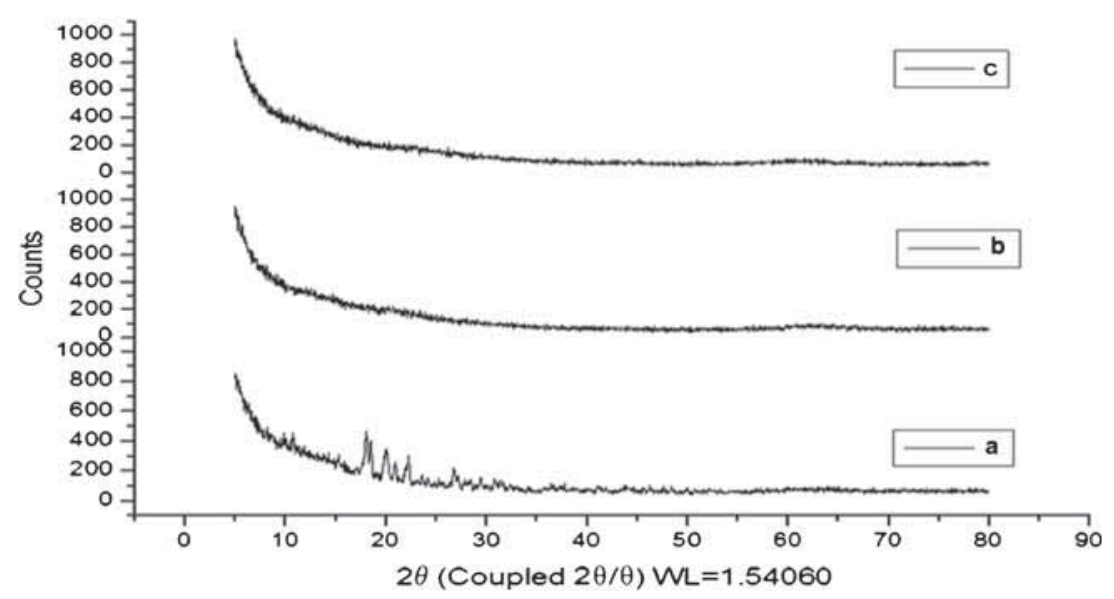

Figure 1. XRD plot of (a) pure glyburide, (b) plane silica nanoparticles and (c) glyburide-loaded silica nanoparticles. 


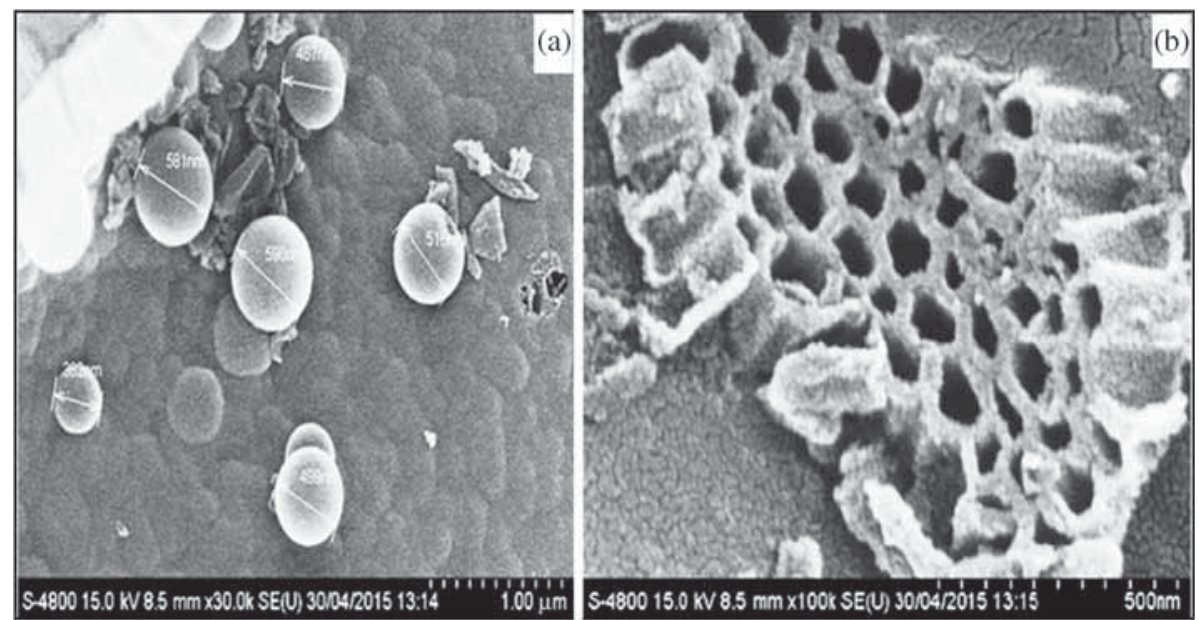

Figure 2. FE-SEM image of glyburide-loaded silica nanoparticles.

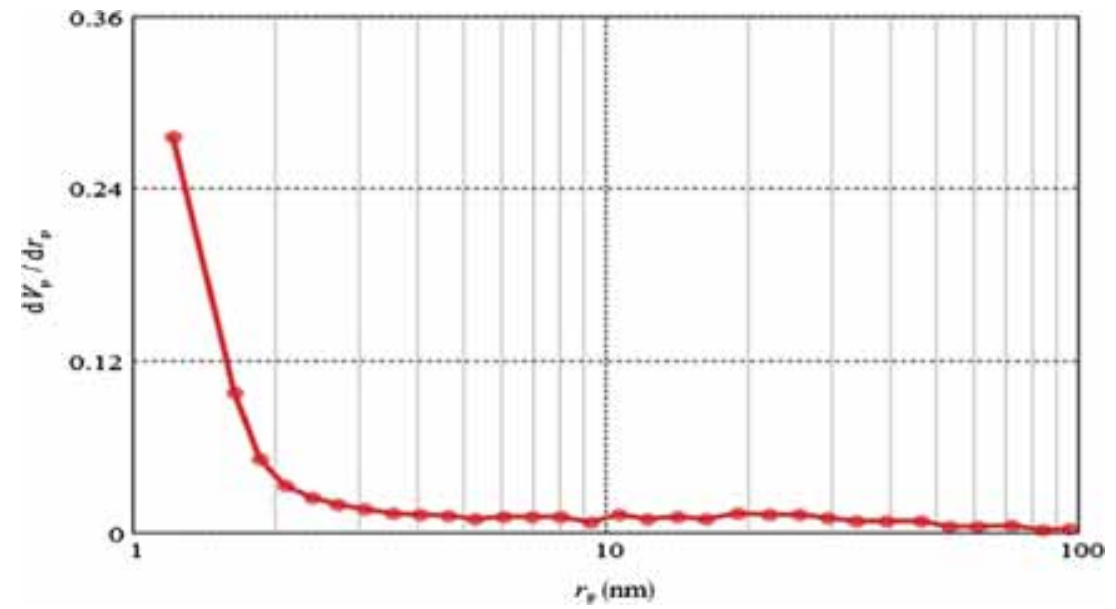

Figure 3. $\mathrm{N}_{2}$ adsorption isotherm.

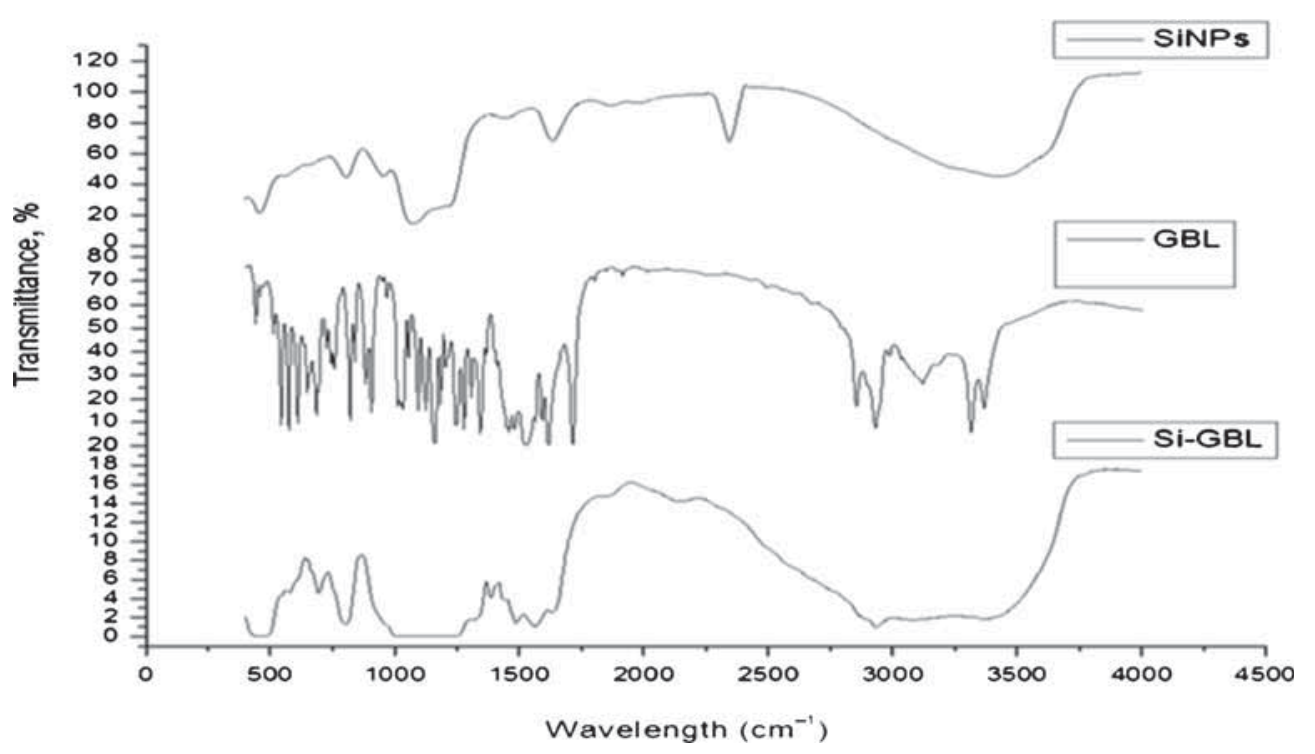

Figure 4. FTIR spectra of plane silica nanoparticles (SiNPs), glyburide (GBL) and glyburide-loaded silica nanoparticles (Si-GBL). 


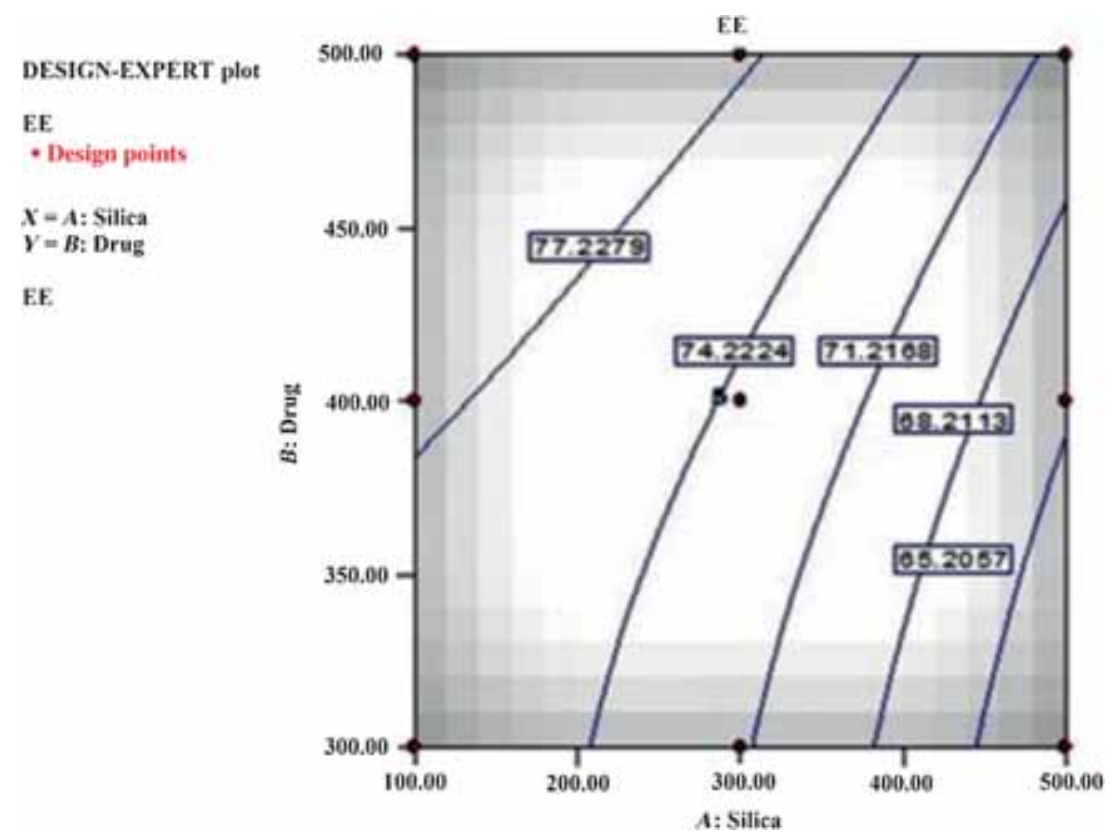

Figure 5. Effect of concentration of silica and glyburide on EE.
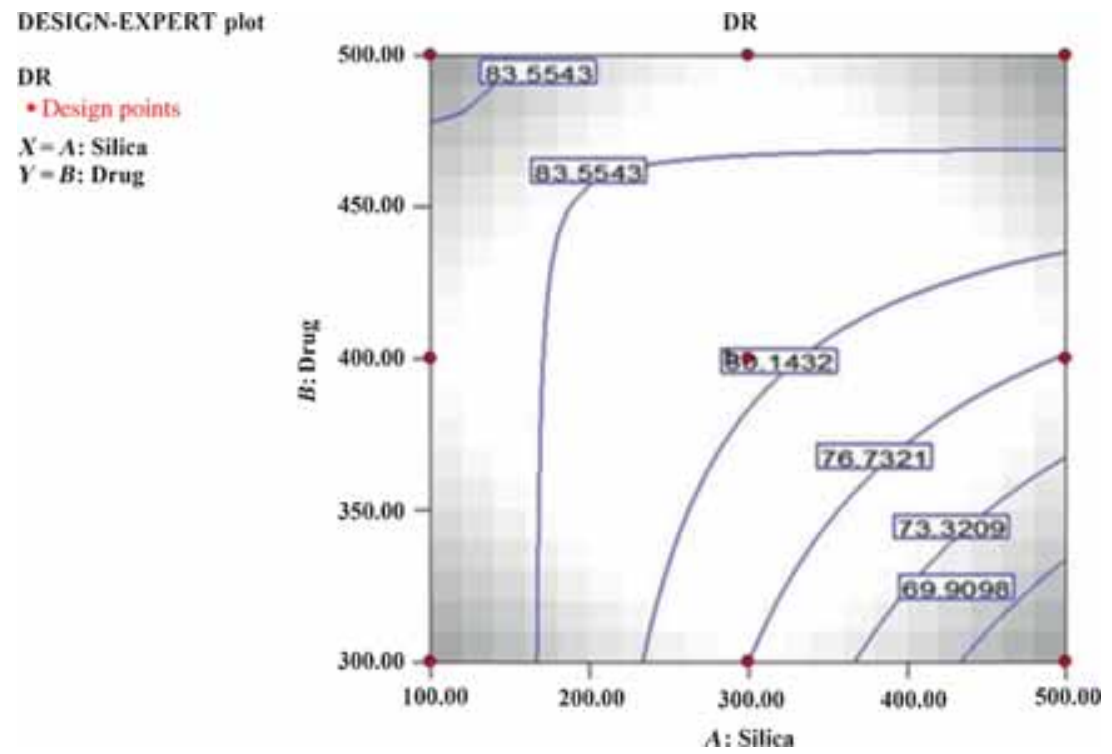

Figure 6. Effect of concentration of silica and glyburide on drug release.

\subsection{Pore size and surface area analysis}

Pore size and surface area were analysed using a BET analyzer. The $\mathrm{N}_{2}$ adsorption isotherm (figure 3 ) indicates that the particles possessed uniform mesoporous and pore size distribution. The mesoporous volume and the surface area of the particles were $0.9328 \mathrm{~cm}^{3} \mathrm{~g}^{-1}$ and $618.15 \mathrm{~m}^{2} \mathrm{~g}^{-1}$, respectively. In addition, the average mesospore size was about $1.21 \mathrm{~nm}$ according to the BJH (Barret, Joner and Halenda) plot method.

\subsection{FTIR spectroscopy}

Figure 4 shows FTIR spectra of plane SiNPs, GBL and Si-GBL. FTIR spectra of the SiNPs show absorption bands arising from asymmetric vibration of $\mathrm{Si}-\mathrm{O}\left(1090 \mathrm{~cm}^{-1}\right)$, asymmetric vibration of $\mathrm{Si}-\mathrm{OH}\left(950 \mathrm{~cm}^{-1}\right)$ and symmetric vibration of $\mathrm{Si}-\mathrm{O}\left(795 \mathrm{~cm}^{-1}\right)$. The absorption bands between 800 and $1260 \mathrm{~cm}^{-1}$ have been described as a superimposition of various $\mathrm{SiO}_{2}$ peaks, $\mathrm{Si}-\mathrm{OH}$ bonding and peaks due to residual organic groups. Water shows an intense characteristic absorption band between 3300 and $3500 \mathrm{~cm}^{-1}$ assigned to $\mathrm{O}-\mathrm{H}$ stretching in $\mathrm{H}$-bonded water. The major peaks of silica as well as GBL that appeared in drug-loaded SiNPs do not indicate existence of a different association from the GBL with $\mathrm{SiO}_{2}$ nanoparticles and any chemical interaction.

A $3^{2}$ response surface methodology was used to study the effect of independent variables on dependent variables with a minimum number of experimental runs. To analyse the effect 
Table 2. Summary of results of regression analysis for responses $Y_{1}$ and $Y_{2}$.

\begin{tabular}{lcccccc}
\hline Models & \multicolumn{1}{c}{$R^{2}$} & Adjusted $R^{2}$ & Predicted $R^{2}$ & Std. dev. & Press & Remarks \\
\hline $\begin{array}{l}\text { Response } Y_{1} \\
\text { Linear }\end{array}$ & 0.927362 & 0.912834 & 0.84472 & 1.45254 & 45.10288 & - \\
2FI & 0.942617 & 0.923489 & 0.800965 & 1.36087 & 57.81226 & - \\
Quadratic & 0.99089 & 0.984382 & 0.966479 & 0.614845 & 9.7366 & Suggests good fit \\
Cubic & 0.990902 & 0.978165 & 0.555914 & 0.726988 & 128.9902 & - \\
Response $Y_{2}$ & & & & & \\
Linear & 0.477106 & 0.372527 & -0.28044 & 4.769576 & 557.0636 & Suggests good fit \\
2FI & 0.808097 & 0.74413 & 0.566584 & 3.045736 & 188.5606 & - \\
Quadratic & 0.838409 & 0.722987 & -0.21872 & 3.169073 & 530.2147 & - \\
Cubic & 0.883223 & 0.719736 & -11.8522 & 3.187616 & 5591.455 & \\
Regression equations of the fitted models & & & & \\
$Y_{1}=73.81-5.97 X_{1}+3.05 X_{2}-2.25 X_{1}^{2}+0.70 X_{2}^{2}+1.05 X_{1} X_{2}$ & & & \\
$Y_{2}=80.82-4.23 X_{1}+4.08 X_{2}+6.00 X_{1} X_{2}$ & & & & \\
\hline
\end{tabular}

Table 3. ANOVA of models for $Y_{1}$ and $Y_{2}$.

\begin{tabular}{lccccr}
\hline Source & DF & Sum of squares & Mean square & $F$-value & $P$-value \\
\hline Model for $Y_{1}$ & 5 & 287.8159 & 287.8159 & 152.2697 & $<0.0001$ \\
$X_{1}$ & 1 & 213.4874 & 213.4874 & 564.7303 & $<0.0001$ \\
$X_{2}$ & 1 & 55.87602 & 55.87602 & 147.8068 & $<0.0001$ \\
$X_{1}^{2}$ & 1 & 13.94574 & 13.94574 & 36.89015 & 0.0005 \\
$X_{2}$ & 1 & 1.36469 & 1.36469 & 3.609965 & 0.0992 \\
$X_{1} X_{2}$ & 1 & 4.431025 & 4.431025 & 11.72123 & 0.0111 \\
Model for $Y_{2}$ & 3 & 351.5683 & 117.1894 & 12.63292 & 0.0014 \\
$X_{1}$ & 1 & 107.5267 & 107.5267 & 11.59128 & 0.0078 \\
$X_{2}$ & 1 & 100.0417 & 100.0417 & 10.78441 & 0.0095 \\
$X_{1} X_{2}$ & 1 & 144 & 144 & 15.52308 & 0.0034 \\
\hline
\end{tabular}

of these independent variables, 2D counter-plots were constructed (figures 5 and 6). The selected independent factors were amount of silica $\left(X_{1} \mathrm{mg}\right)$ and $\mathrm{GBL}\left(X_{2} \mathrm{mg}\right)$, whereas EE (\%) and DR (\%) were selected as dependent variables. Experimental runs at three levels listed in table 1 show the EE in the range of $62-80 \%$ and DR in the range of $68.8-$ $87.8 \%$ over $24 \mathrm{~h}$. The effects of independent variables are investigated by deriving polynomial equations and counterplots. Correlation coefficient $\left(R^{2}\right)$ value was 0.9908 for the quadratic model of response $Y_{1}$ and 0.8080 for the 2FI model of response $Y_{2}$, signifying good fit (shown in table 2). The equations obtained for the $\mathrm{EE}\left(Y_{1}\right)$ and $\mathrm{DR}\left(Y_{2}\right)$ are

$Y_{1}=73.81-5.97 X_{1}+3.05 X_{2}-2.25 X_{1}^{2}+0.70 X_{2}^{2}+1.05 X_{1} X_{2}$,

$$
Y_{2}=80.82-4.23 X_{1}+4.08 X_{2}+6.00 X_{1} X_{2} .
$$

A positive and a negative value in the equations represent the synergistic and antagonistic effect, respectively. Table 3 shows the ANOVA of the model for $Y_{1}$ and $Y_{2}$. The quadratic equation of $\mathrm{EE}\left(Y_{1}\right)$ indicated that it was affected by the independent variables like $X_{1}, X_{2}, X_{1}^{2}$ and $X_{1} X_{2}$. Similarly, the 2FI equation of DR $\left(Y_{2}\right)$ signifies that it was affected by the independent variables like $X_{1}, X_{2}$ and $X_{1} X_{2}$. The effects of these independent variables on EE and DR were significant at $P<0.05$. Both the models were significant at $F$ values of 152.26 and 12.63 at $P<0.05$. Table 4 presents the diagnostic
Table 4. Diagnostics case statistics for various response variables.

\begin{tabular}{|c|c|c|c|c|}
\hline Batch no. & $\begin{array}{l}\text { Response } \\
\text { variables }\end{array}$ & Actual value & $\begin{array}{l}\text { Predicted } \\
\text { value }\end{array}$ & Residual \\
\hline \multirow[t]{2}{*}{$\mathrm{F} 1$} & $Y_{1}$ & 70.21 & 70.41 & -0.20 \\
\hline & $Y_{2}$ & 87.80 & 86.67 & 1.13 \\
\hline \multirow[t]{2}{*}{$\mathrm{F} 2$} & $Y_{1}$ & 74.00 & 73.81 & 0.19 \\
\hline & $Y_{2}$ & 82.00 & 80.82 & 1.18 \\
\hline \multirow[t]{2}{*}{ F3 } & $Y_{1}$ & 66.00 & 65.60 & 0.40 \\
\hline & $Y_{2}$ & 70.00 & 76.58 & 6.58 \\
\hline \multirow[t]{2}{*}{$\mathrm{F} 4$} & $Y_{1}$ & 73.00 & 73.81 & -0.81 \\
\hline & $Y_{2}$ & 84.00 & 80.82 & 3.18 \\
\hline \multirow[t]{2}{*}{ F5 } & $Y_{1}$ & 73.00 & 73.81 & -0.81 \\
\hline & $Y_{2}$ & 82.00 & 80.82 & 1.18 \\
\hline \multirow[t]{2}{*}{ F6 } & $Y_{1}$ & 74.40 & 73.81 & 0.59 \\
\hline & $Y_{2}$ & 82.90 & 80.82 & 2.08 \\
\hline \multirow[t]{2}{*}{ F7 } & $Y_{1}$ & 62.00 & 62.20 & -0.20 \\
\hline & $Y_{2}$ & 68.80 & 66.50 & 2.30 \\
\hline \multirow[t]{2}{*}{ F8 } & $Y_{1}$ & 76.00 & 76.24 & -0.24 \\
\hline & $Y_{2}$ & 87.00 & 86.97 & 0.035 \\
\hline \multirow[t]{2}{*}{ F9 } & $Y_{1}$ & 73.80 & 73.81 & 0.013 \\
\hline & $Y_{2}$ & 82.60 & 80.82 & 1.78 \\
\hline \multirow[t]{2}{*}{ F10 } & $Y_{1}$ & 80.00 & 80.23 & -0.23 \\
\hline & $Y_{2}$ & 82.00 & 83.13 & -1.13 \\
\hline \multirow[t]{2}{*}{ F11 } & $Y_{1}$ & 71.90 & 71.46 & 0.44 \\
\hline & $Y_{2}$ & 74.00 & 76.73 & -2.73 \\
\hline \multirow[t]{2}{*}{ F12 } & $Y_{1}$ & 78.00 & 77.53 & 0.47 \\
\hline & $Y_{2}$ & 83.00 & 85.05 & -2.05 \\
\hline \multirow[t]{2}{*}{ F13 } & $Y_{1}$ & 78.00 & 77.57 & 0.43 \\
\hline & $Y_{2}$ & 84.50 & 84.90 & -0.40 \\
\hline
\end{tabular}




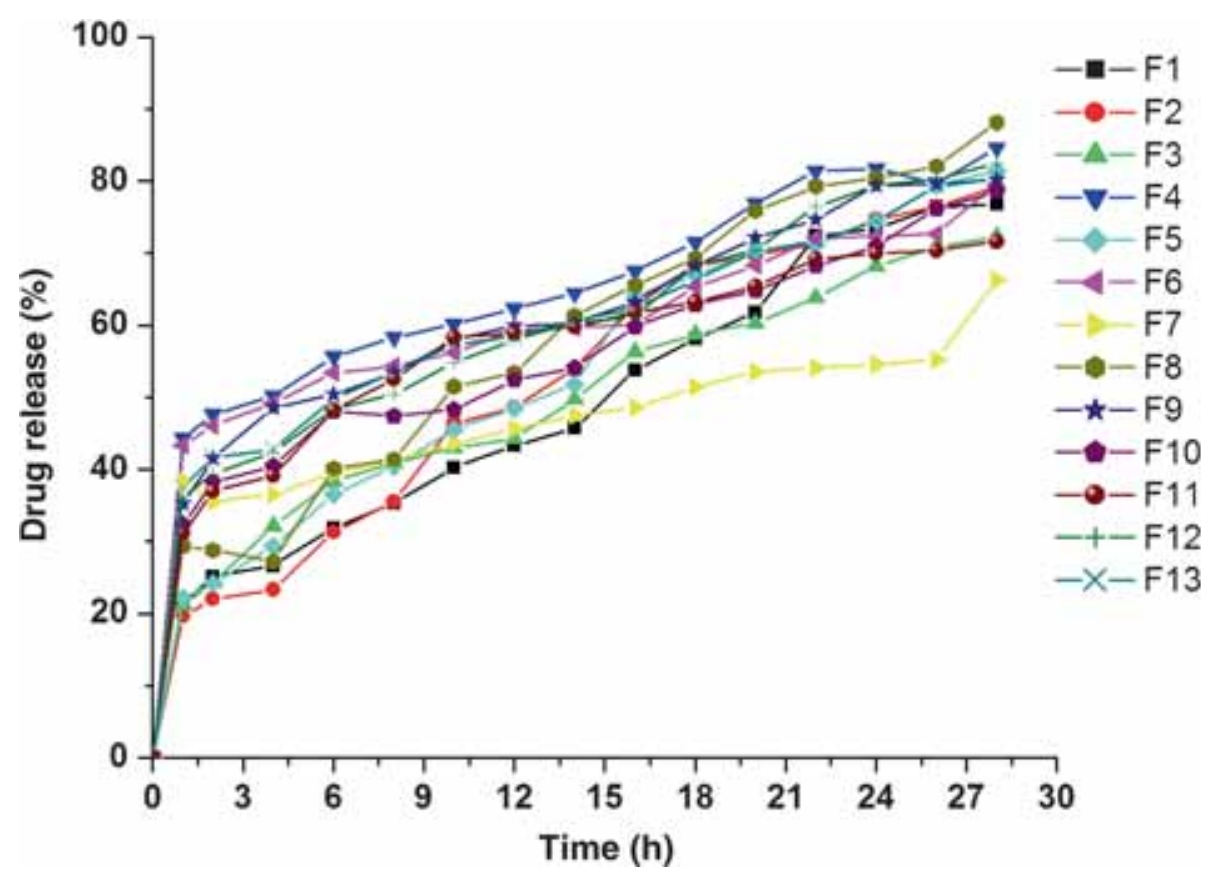

Figure 7. Drug release profile of glyburide-loaded silica nanoparticles.

case statistics for various response variables with actual, predicted and residual values. The prediction error was calculated by comparing the resultant experimental value to predicted value $[23,24]$. The difference obtained between actual and predicted values was small, suggesting that the model was well fitted.

\subsection{EE and DR}

The 2D counter-plot in figure 5 shows the effect of silica and GBL factors on EE. When silica concentration was at $(-1)$ level and drug concentration at $(+1)$ level the EE was $80 \%$. The EE increases with increase in the concentration of GBL and decreases with increase in the concentration of silica. The 2D counter-plot in figure 6 shows the effect of both factors (i.e., concentration of silica and concentration of drug) on DR, whereas figure 7 displays the pattern of DR percent in $24 \mathrm{~h}$. From the figure it is observed that the DR is in the range of $74-87.8 \%$ for all 13 batches and increases with an increase in the concentration of GBL. To diminish the potential risk, the minimum effective dose should be used for the shortest possible duration.

\section{Conclusion}

The present study reveals the development of Si-GBL. SiNPs having pores on their surface were successfully synthesized using response surface methodology. The mathematical model developed for the response using statistical analysis quantitatively expresses the influence of selected variables on the responses. The encapsulation efficiency was in the range of $62 \%(\mathrm{~F} 7)$ to $78 \%$ (F12). The formulation shows the sustained drug release action $(68.8-87.8 \%)$ up to $24 \mathrm{~h}$. No drug and excipients interaction was reported in FTIR spectra; XRD revealed that the GBL was dispersed at molecular level in SiNPs. The $\mathrm{N}_{2}$ absorption isotherm of BET analysis significantly shows pores on SiNPs with average pore size of about $1.21 \mathrm{~nm}$. Nanoparticles developed by this method may represent a promising approach for effective sustained release delivery of GBL.

\section{Acknowledgement}

We are very much thankful to TEQIP-II for providing financial support to carry out this research work. We are also thankful to USV Ltd. Mumbai, for providing a gift sample of the drug and Metrohm India Ltd. for surface area as well as porosity determination of GBL-loaded SiNPs.

\section{Conflict of interest}

The authors declare no conflict of interest.

\section{References}

[1] Kwon S, Singh R K, Perez R A, Abou Neel E A, Kim H-W and Chrzanowski W 2013 J. Tissue Eng. 4 2041731413503357

[2] Yuan X and Cormack A 2003 J. Non-Cryst. Solids 31931

[3] Zhang Q, Wang X, Li P-Z et al 2014 Adv. Funct. Mater. 24 2450

[4] He Y and Yu X 2007 Mater. Lett. 612071

[5] Graf C, Gao Q, Schütz I et al 2012 Langmuir 287598

[6] Ribeiro T, Baleizao C and Farinha J 2014 Materials 73881

[7] Zoeller T, Dressman J B and Klein S 2012 Int. J. Pharm. 430176 
[8] Mokale V, Patil K, Khatik T and Sutar Y 2013 Asian J. Pharmacol. 7111

[9] Ashcroft F M 2005 J. Clin. Invest. 1152047

[10] Inzucchi S E, Bergenstal R M, Buse J B et al 2012 Diabetes Care 351364

[11] Malmberg K 1997 BMJ 3141552

[12] Jonsson A, Rydberg T, Ekberg G, Hallengren B and Melander A 1994 Diabetes Care 17142

[13] Langer O 2002 Semin. Perinatol. 26215

[14] Xinyue H, Neil P Y and Helen E T 2014 Nanomater. Nanotechnol. 41

[15] Kalpesh S, Ana L, Daniel S, Tito T and Joao A P C 2011 Green Chem. 13340

[16] Haijiao Z, Zhiyong L, Panpan X, Ruofei W and Zheng J 2010 Chem. Commun. 466783
[17] Nayak A K, Pal D, Pradhan J and Hasnain M S 2013 Int. J. Biol. Macromol. 54144

[18] Pritam P, Khairnar G and Naik J 2015 Chem. Eng. Res. Des. 10498

[19] Shanbagh P, Abhyankar M, Shah H, Kalsulkar S, Tripathi G and Belge P 2011 PHARMA Rev. 176

[20] Yadava S K, Patil J S, Mokale V J and Naik J B 2014 J. SolGel Sci. Technol. 7160

[21] Deshmukh R K and Naik J B 2013 J. Pharm. Innov. 8276

[22] Das S, Ng W K, Kanaujia P, Kim S and Tan R B H 2011 Colloids Surf. B Biointerfaces $\mathbf{8 8} 483$

[23] Chopra S, Patil G V and Motwani S K 2007 Eur. J. Pharm. Biopharm. 6673

[24] Montgomery D C 2008 Introduction to statistical quality control 4th edn (New York: Wiley) 